\title{
Nutritional status and subsequent all-cause mortality in men and women aged 75 years or over living in the community
}

\author{
Xueli Jia ${ }^{1}$, Lorna S. Aucott ${ }^{2}$ and Geraldine McNeill ${ }^{1 *}$ \\ ${ }^{1}$ Department of Environmental and Occupational Medicine and \\ ${ }^{2}$ Department of Public Health, University of Aberdeen, Foresterhill, Aberdeen AB25 2ZD, UK
}

(Received 29 September 2006 - Revised 26 February 2007 - Accepted 26 February 2007)

\begin{abstract}
We prospectively investigated relationships between blood markers of $\mathrm{Fe}$, vitamin $\mathrm{B}_{12}$, folate, vitamin $\mathrm{C}$ and vitamin $\mathrm{D}$ status and subsequent allcause mortality in 208 men and 191 women aged 75 years or over living in the community in Aberdeen, Scotland. The participants had been recruited for a cross-sectional study in 1999-2000 when they completed health and lifestyle questionnaires and had blood samples taken for analysis of serum ferritin, serum vitamin $B_{12}$, erythrocyte folate, plasma vitamin $\mathrm{C}$ and serum 25-hydroxycholecalciferol. Mortality was ascertained on national databases up to December 2005, with a median time of follow up of $69 \cdot 2$ (range 1.0-79.9) months. Participants were divided into sexspecific quintiles of baseline levels for each nutrient, and hazard ratios were estimated with Cox proportional hazard models adjusted for age and sex with the significance of linear trends in the associations assessed by logistic regression. There was no significant association between blood markers of $\mathrm{Fe}$, vitamin $\mathrm{B}_{12}$ or folate status at baseline and mortality, but vitamin D status at baseline was inversely related to mortality $(P$ for trend $<0.001)$. For vitamin $C$ there was no evidence of a linear trend but participants in the lowest quintile of plasma levels had a significantly higher risk of death than those in the highest quintile. Randomized controlled trials of lifestyle changes which improve vitamin status are needed to assess whether these associations could be causal.
\end{abstract}

Nutritional status: Vitamin D: Vitamin C: Iron: Mortality: Elderly

Nutritional status declines in old age. In the UK National Diet and Nutrition Survey the proportion of free-living individuals aged 75 years old with biochemical evidence of deficiency was approximately $8 \%$ for $\mathrm{Fe}, 10 \%$ for vitamin $\mathrm{B}_{12}, 30 \%$ for folate and $18 \%$ for vitamin $\mathrm{C}$, while $10 \%$ men and $20 \%$ women were deficient in vitamin $\mathrm{D}^{1}$. The high prevalence of nutritional deficiency in old individuals is partly due to reduced appetite and lower physical activity as a result of musculo-skeletal and other health problems. The decrease in energy and nutrient intake may be compounded by malabsorption due to poor function of the digestive system or side effects of medication.

There is limited evidence for a relationship between low nutritional status and subsequent mortality in old individuals. A 29-year cohort study based on the 1969 Busselton Health Survey in Western Australia found no association between folate or vitamin $\mathrm{B}_{12}$ status and all-cause mortality ${ }^{2}$. By contrast, a 4-year cohort study of individuals over 75 years old living in the community in the UK found that those in the lowest quintile of vitamin $\mathrm{C}$ status had a significantly lower hazard ratio for all-cause mortality than those in the highest quintile ${ }^{3}$. A beneficial effect of vitamin $\mathrm{C}$ was also suggested by large cohort studies which included younger adults $^{4,5}$. A 31-month follow up of men and women living in residential age care facilities in Sydney, Australia found that vitamin D status was significantly associated with allcause mortality after adjustment for age and sex, though this effect was not seen after further adjustment for confounding variables such as health status at baseline ${ }^{6}$.

In an earlier study designed to identify predictors of poor nutritional status in later life, we obtained measurements of blood markers of $\mathrm{Fe}$, vitamin $\mathrm{B}_{12}$, folate, vitamin $\mathrm{C}$ and vitamin D status in 398 men and women over 75 years old living in the community. In the present study we investigated possible associations between these blood nutrient levels and mortality in the following 5 years.

\section{Methods \\ Participants and measurement of nutritional status}

A full description of the recruitment of subjects and methods of measurement of blood analytes has been reported elsewhere ${ }^{7}$. Briefly, a random sample of individuals aged 75 years old or over living in the community in Aberdeen, Scotland were selected from the Community

\footnotetext{
Abbreviations: CHI, Community Health Index; GROS, General Register Office for Scotland; ICD, International Classification of Disease; 25-OHD, 25-hydroxycholecalciferol.

* Corresponding author: Dr Geraldine McNeill, fax +44 1224 551826, email g.mcneill@abdn.ac.uk
} 
Health Index (CHI), a comprehensive list of all patients registered with family doctors in the UK National Health Service. A small number of individuals with terminal illness or severe dementia that could have led to difficulties cooperating with the study were excluded by their family doctor. Initially, 821 men and 1122 women were invited to participate by letter and $208(25 \%)$ men and 197 (17\%) women agreed to participate and completed the study. A 114-item health and lifestyle questionnaire (including sunlight exposure, supplement use and intake of selected foods) was administered in the participants' homes by a research nurse who also measured height and weight and took a venous blood sample. The blood samples were taken in the morning after a light breakfast without fruit juice or breakfast cereal. The samples were treated with EDTA and stored at $-70^{\circ} \mathrm{C}$ before analysis of plasma vitamin $\mathrm{C}$ by HPLC and serum 25-hydroxycholecalciferol (25-OHD), vitamin $\mathrm{B}_{12}$ and ferritin and erythrocyte folate by RIA.

\section{Mortality}

Deaths of participants were determined up to 12 December 2005 by matching with the Grampian CHI and records kept by the General Register Office for Scotland (GROS) ${ }^{8}$, which incorporates information on deaths occurring in England. Seven participants who were recorded as having died on the CHI but not with the GROS were assumed to have died. Four participants who were recorded on the $\mathrm{CHI}$ as having moved out of Scotland but were not recorded as having died with the GROS were assumed to be still living. The GROS also supplied information on causes of death, with the 10th International Classification of Disease (ICD-10) used for deaths which occurred after November 1999 and ICD-9 used for those occurring before this time.

\section{Data analysis}

For all models, survival time was a continuous variable which ranged 0-80 months from the baseline measurements. Sexspecific quintiles of blood markers of nutritional status were created, with quintiles ranging from 1 (lowest) to 5 (highest). Two participants with the highest serum ferritin levels (1232.0 and $1847.0 \mu \mathrm{g} / \mathrm{l}$ ) were excluded from the analysis for $\mathrm{Fe}$ as these levels were assumed to reflect recent infection. The relationship between baseline nutritional status and mortality was assessed using a test for linear trend across the quintiles in logistic regression. Hazard ratios were estimated using Cox proportional hazard models for quintiles $1-4$ referent to quintile 5. The analysis was carried out in all subjects together and in men and women separately. The sample size provided $80 \%$ power at a $5 \%$ significance level to detect hazard ratios of 2.7 or greater between the highest and any other quintile, assuming a mortality rate of 60/1000 individual years. Adjustment for confounding variables that could affect mortality was included in models $1-3$. In model 1 , results were adjusted for age and sex. In an effort to control for pre-existing illness, self-perceived health status and taking five or more kinds of medicine were added into model 2. Model 3 adjusted the results further by adding self-reported heart disease and/or diabetes at baseline.
To test the possibility that any relationship between vitamin D status and survival could be the result of reverse causation, with participants who were ill having lower sunlight exposure as a result of their illness, we assessed whether associations between survival and vitamin D status could be attenuated by including two covariates which influence vitamin D levels, i.e. sunlight exposure and use of a supplement containing vitamin D, either separately (models 4 and 5 respectively) or in combination (model 6). Sunlight exposure was estimated from three variables in the baseline survey: season of blood sampling, frequency of sunbathing and participation in outdoor physical activity.

All analysis was carried out using SPSS version 14.0 (SPSS Inc., Chicago, IL, USA).

\section{Results}

Overall, seventy-one men $(34.3 \%)$ and fifty-eight women (30.4\%) had died by 12 December 2005. The median time of follow up was 69.2 (range 1.0-79.9) months. Among those who had died, $32.8 \%$ men and $25.9 \%$ women had died from IHD (ICD-10 codes I20-I25 or ICD-9 codes $410-414), 11.9 \%$ men and $24.0 \%$ women had died from cerebrovascular disease (ICD-10 codes I60-I69) and 30.0\% men and $15.5 \%$ women had died from cancer (ICD-10 codes C00C97). The average mortality rate during the follow-up period in the study participants was $56 / 1000$ population per year (61/ 1000 in men and 53/1000 in women). This was lower than the mortality rate of the population of Grampian, Scotland aged 75 years old or over in 2005 of 93/1000 in men and 80/ 1000 in women ${ }^{8}$, which probably reflects the fact that those who participated in the original study were more likely to have been in good health at the time of recruitment than those who did not participate.

Table 1 presents the general characteristics of the study participants. More than half of the participants reported having heart disease in 1999-2000 while 13.3\% were supplement users (defined as taking any kind of nutrient supplement at least once per d). Men had a higher income, a better self-perceived health status, were more physically active and were more likely to spend time outdoors in sunny weather than women. Women had higher plasma vitamin $C$ status than men while men had higher levels of serum ferritin, erythrocyte folate and serum 25-OHD. Survivors were significantly younger, had a slightly higher BMI, were less likely to have heart disease and/or diabetes at baseline, were less likely to be taking more than five kinds of medicine, generally had a better self-perceived health status, were more likely to be physically active, spend time outdoors in sunny weather and to take a supplement containing vitamin D than those who died. Survivors also had significantly higher plasma vitamin $\mathrm{C}$ and serum 25-OHD levels than those who had died.

Table 2 shows the hazard ratios for mortality across the quintiles and the significance of linear trends. There was no trend in the associations between quintiles of serum ferritin, serum vitamin $B_{12}$, erythrocyte folate or plasma vitamin $C$ status and mortality but for vitamin $C$ the participants in the lowest quintile had significantly higher mortality than those in the highest quintile in all three models. Serum 25-OHD had a highly significant inverse 
Table 1. General characteristics of study participants ( $n$ 398)

(Medians and ranges)

\begin{tabular}{|c|c|c|c|c|c|c|c|c|c|c|c|c|}
\hline & \multicolumn{2}{|c|}{ All ( $n$ 398) } & \multicolumn{2}{|c|}{ Men ( $n$ 207) } & \multicolumn{2}{|c|}{ Women ( $n$ 197) } & \multirow[b]{2}{*}{$P^{*}$} & \multicolumn{2}{|c|}{ Survivors ( $n$ 269) } & \multicolumn{2}{|c|}{ Non-survivors ( $n$ 129) } & \multirow[b]{2}{*}{$P \dagger$} \\
\hline & Median & Range & Median & Range & Median & Range & & Median & Range & Median & Range & \\
\hline Age when recruited (years) & 80 & 75,96 & 79 & 75,93 & 80 & 75,96 & 0.34 & 79 & 75,91 & 81 & 75,96 & $<0.001$ \\
\hline $\begin{array}{l}\text { BMI when recruited } \\
\left(\mathrm{kg} / \mathrm{m}^{2}\right) \ddagger\end{array}$ & $25 \cdot 4$ & $23 \cdot 4,27 \cdot 7$ & $25 \cdot 3$ & $16 \cdot 6,35 \cdot 0$ & $25 \cdot 6$ & $16 \cdot 6,38 \cdot 3$ & 0.17 & $25 \cdot 6$ & $16 \cdot 6,38 \cdot 3$ & $24 \cdot 8$ & $16 \cdot 6,35 \cdot 7$ & 0.02 \\
\hline Survival time (months) & 69.2 & $1 \cdot 0,79.9$ & 68.5 & $1 \cdot 0,79 \cdot 9$ & 69.6 & $1.7,79.9$ & 0.73 & $72 \cdot 4$ & $62 \cdot 1,79 \cdot 9$ & $43 \cdot 3$ & $1 \cdot 0,76 \cdot 6$ & $<0.001$ \\
\hline Smoking (\%) & & 3 & & 7 & & 8 & 0.26 & & $6 \cdot 3$ & & 9.3 & 0.28 \\
\hline $\begin{array}{l}\text { Income } \leq 200 \text { GBP per } \\
\text { week }(\%)\end{array}$ & & 9.7 & & 4.0 & & 6.0 & 0.02 & & $49 \cdot 1$ & & $51 \cdot 2$ & 0.70 \\
\hline Living alone (\%) & & 1.0 & & 4.3 & & 9.1 & $<0.001$ & & 50.6 & & 51.9 & 0.74 \\
\hline $\begin{array}{l}\text { Self-reported heart disease } \\
(\%)\end{array}$ & & 3.3 & & 9.4 & & 7.1 & 0.63 & & $52 \cdot 0$ & & $71 \cdot 3$ & $<0.001$ \\
\hline Self-reported diabetes (\%) & & 3 & & 2 & & $\cdot 2$ & 0.10 & & 3.3 & & $12 \cdot 4$ & $<0.001$ \\
\hline $\begin{array}{l}\text { Taking } \geq \text { five kinds of } \\
\text { medicine }(\%)\end{array}$ & & 5.6 & & 5.1 & & 6.2 & 0.81 & & $19 \cdot 0$ & & 39.5 & $<0.001$ \\
\hline \multicolumn{13}{|c|}{ Self-perceived health status (\%) } \\
\hline Excellent & & 1.3 & & 6.9 & & 2 & & & 13.4 & & 7.0 & \\
\hline Very good & & 5.9 & & 4.3 & & 9.8 & & & $42 \cdot 4$ & & $25 \cdot 6$ & \\
\hline Good & & 0.4 & & 9.0 & & 1.9 & $<0.001$ & & 29.4 & & $32 \cdot 6$ & $<0.001$ \\
\hline Fair & & 7.6 & & 5.9 & & 9.4 & & & $12 \cdot 3$ & & 28.7 & \\
\hline Poor & & 8 & & .9 & & .7 & & & $2 \cdot 6$ & & $6 \cdot 2$ & \\
\hline \multicolumn{13}{|l|}{ Physical activity (\%)§ } \\
\hline Indoor & & 1.6 & & 8 & & 6.8 & & & $13 \cdot 0$ & & 8.5 & \\
\hline Outdoor & & 3.6 & & 9.1 & & 7.3 & $<0.001$ & & 33.1 & & $19 \cdot 4$ & $<0.001$ \\
\hline Both & & 5.8 & & 1.3 & & .9 & & & $19 \cdot 0$ & & 9.3 & \\
\hline None & & 4.0 & & 2.9 & & 6.0 & & & 34.9 & & $62 \cdot 8$ & \\
\hline \multicolumn{13}{|l|}{ Outdoors in sunny weather (\%) } \\
\hline Often & & 3.9 & & 4.1 & & 9.1 & & & 82.5 & & $65 \cdot 1$ & \\
\hline Occasionally & & 4.1 & & 2.1 & & 6.2 & $<0.001$ & & 12.6 & & $17 \cdot 1$ & $<0.001$ \\
\hline Seldom or never & & 0 & & .9 & & 4.7 & & & 4.8 & & $17 \cdot 8$ & \\
\hline \multicolumn{13}{|l|}{ Supplement user (\%)\| } \\
\hline All kinds & & 3.3 & & 2.1 & & 4.7 & 0.45 & & 14.5 & & $10 \cdot 9$ & 0.32 \\
\hline $\mathrm{Fe}$ & & 0 & & .7 & & 3 & 0.57 & & 7.4 & & 6.2 & 0.65 \\
\hline $\begin{array}{l}\text { Vitamin } B_{12} \text { and/or injec- } \\
\text { tion }\end{array}$ & & 2.6 & & 2.6 & & $2 \cdot 2$ & 0.55 & & 13.8 & & $10 \cdot 1$ & 0.23 \\
\hline Folic acid & & 0 & & 7 & & 4 & 0.80 & & $10 \cdot 0$ & & $7 \cdot 0$ & 0.32 \\
\hline Vitamin C & & 3.3 & & 2.1 & & 4.7 & 0.45 & & 14.5 & & $10 \cdot 9$ & 0.32 \\
\hline Vitamin D & & 3.9 & & $4 \cdot 2$ & & 9.8 & 0.20 & & $31 \cdot 2$ & & $17 \cdot 8$ & 0.005 \\
\hline $\begin{array}{l}\text { Had at least two } \\
\text { portions of fruit and } \\
\text { vegetables in the } \\
\text { previous day (\%) }\end{array}$ & & 4.1 & & 2.5 & & 5.9 & 0.43 & & $75 \cdot 1$ & & $72 \cdot 1$ & 0.52 \\
\hline \multicolumn{13}{|l|}{ Season of blood sampling (\%) } \\
\hline $\begin{array}{l}\text { Summer (April-Septem- } \\
\text { ber) }\end{array}$ & & 3.8 & & 4.7 & & 8.2 & $<0.001$ & & $55 \cdot 4$ & & $59 \cdot 7$ & 0.42 \\
\hline Winter (October-March) & & 3.2 & & $5 \cdot 3$ & & 1.8 & & & 44.6 & & $40 \cdot 3$ & \\
\hline Serum ferritin $(\mu \mathrm{g} / \mathrm{l}) \boldsymbol{q}$ & 58.2 & $3 \cdot 8,861 \cdot 8$ & 74.0 & $3 \cdot 8,675 \cdot 7$ & $47 \cdot 4$ & $4 \cdot 4,861 \cdot 8$ & $<0.001$ & 61.9 & $4 \cdot 0,861 \cdot 8$ & $57 \cdot 2$ & $3 \cdot 8,717 \cdot 1$ & 0.47 \\
\hline Serum vitamin $B_{12}(\mathrm{pmol} / \mathrm{l})$ & 246 & 39,1476 & 245 & 39,1476 & 247 & 74,1476 & 0.59 & 246 & 57,1476 & 245 & 39,738 & 0.66 \\
\hline Erythrocyte folate $(\mathrm{nmol} / \mathrm{l})$ & 580 & 66,2266 & 606 & 66,2266 & 544 & 107,2178 & 0.02 & 564 & 107,2266 & 610 & 66,2266 & 0.56 \\
\hline
\end{tabular}


relationship with risk of death, with participants in the lowest quintile having over twice the risk of those in the highest quintile.

When the analysis for vitamin D was repeated for men and women separately, the trends remained significant in both men and women (both $P=0.02$ ) (Figs. 1 (a) and (b) and Table 3).

When sunlight exposure and vitamin D supplementation were added into the models the hazard ratios were attenuated but the trend across quintiles was still significant (Table 4).

\section{Discussion}

\section{Comparison with other studies}

The results of the present study are consistent with an inverse association between vitamin D status and mortality. They also provide some evidence for an inverse association between vitamin $\mathrm{C}$ status and mortality, but no evidence for any association between $\mathrm{Fe}$, vitamin $\mathrm{B}_{12}$ or folate status and mortality. The lack of association between blood $\mathrm{Fe}$ status and mortality is consistent with results from the NHANES II mortality study ${ }^{9}$ in which associations were found only in those who had elevated Fe storage with high dietary $\mathrm{Fe}$ intake or high meat consumption, as only $2.9 \%$ men and $7.9 \%$ women in the present study had elevated $\mathrm{Fe}$ storage (defined as ferritin levels above $300 \mu \mathrm{g} / \mathrm{l}$ in men or above $150 \mu \mathrm{g} / \mathrm{l}$ in women $\left.{ }^{10}\right)$. The lack of association between vitamin $B_{12}$ or folate status and mortality is consistent with the results from the Busselton Health Survey ${ }^{2}$. The finding that those in the highest quintile of plasma vitamin $\mathrm{C}$ status had a significantly lower risk of death than those in the highest quintile is consistent with the results from other studies $^{3-5}$, though in the present study there was no significant trend across the quintiles, as was seen in the other studies.

One possible explanation for the inverse association between blood vitamin $\mathrm{D}$ status and mortality is that participants who had serious illness at baseline would have spent more time indoors which would lead to a low vitamin D status. However, this would be expected to lead to a greater association with survival in the early years of follow up whereas the slope of the survival curves for the first few years of follow up was similar to that in the later years (Figs. 1 (a) and 1 (b)). The fact that the association was attenuated when sunlight exposure and taking supplements containing vitamin $\mathrm{D}$ were included in the model also supports the possibility that the association could be causal. However, the association was not abolished in these models, which could reflect residual confounding by factors such as dietary intake or hormonal status, which were not measured in the original survey, or that sunlight exposure was not assessed accurately by the questionnaire. The results for vitamin $\mathrm{D}$ in the present study are similar to those of a study of participants of mean age 83 years carried out in Australia $^{6}$ who had lower serum 25-OHD levels than participants in the present study despite living at lower latitude $\left(33.6^{\circ} \mathrm{S}\right)$ than Aberdeen $\left(57.9^{\circ} \mathrm{N}\right)$. In the Sydney study the hazard ratio for the vitamin D-sufficient group compared with that of the deficient group (serum 25-OHD 
Table 2. Hazard ratios (HR) of risk of death referent to the highest quintile of baseline nutritional status and significance of linear trends across sexspecific quintiles for men and women combined

\begin{tabular}{|c|c|c|c|c|c|c|c|c|c|c|}
\hline Quintile & Men & Women & $n^{\star}$ & Deaths $(n)$ & $\mathrm{HR} \dagger$ & $95 \% \mathrm{Cl}$ & $\mathrm{HR} \ddagger$ & $95 \% \mathrm{Cl}$ & HR§ & $95 \% \mathrm{Cl}$ \\
\hline \multicolumn{11}{|c|}{ Serum ferritin $(\mu \mathrm{g} / \mathrm{l})$} \\
\hline 1 & $3 \cdot 8-27 \cdot 4$ & $4.4-23.3$ & 79 & 30 & $1 \cdot 28$ & $0 \cdot 75,2 \cdot 17$ & $1 \cdot 12$ & $0.65,1.93$ & $1 \cdot 16$ & $0.67,1.99$ \\
\hline 2 & $27 \cdot 5-57 \cdot 7$ & $23 \cdot 4-38 \cdot 7$ & 80 & 25 & 0.89 & $0.51,1.55$ & 0.79 & $0.45,1.39$ & 0.80 & $0.46,1.40$ \\
\hline 3 & $57 \cdot 8-95 \cdot 6$ & $38 \cdot 8-58 \cdot 8$ & 80 & 23 & 0.90 & $0.51,1.59$ & 0.84 & $0.47,1.49$ & 0.84 & $0.47,1.48$ \\
\hline 4 & $95 \cdot 7-149 \cdot 2$ & $58.9-91.5$ & 80 & 26 & 1.01 & $0.58,1.74$ & 1.05 & $0.60,1.82$ & $1 \cdot 12$ & $0.64,1.95$ \\
\hline 5 & $149 \cdot 3-675 \cdot 7$ & $91 \cdot 6-861 \cdot 8$ & 77 & 24 & \multirow{2}{*}{\multicolumn{2}{|c|}{$\begin{array}{c}1 \\
0.46\end{array}$}} & \multicolumn{2}{|r|}{1} & \multirow{2}{*}{\multicolumn{2}{|c|}{$\begin{array}{c}1 \\
0.79\end{array}$}} \\
\hline$P$ for tren & & & & & & & & 0.88 & & \\
\hline \multicolumn{11}{|c|}{ Serum vitamin $\mathrm{B}_{12}(\mathrm{pmol} / \mathrm{l})$} \\
\hline 1 & $39 \cdot 1-180 \cdot 6$ & $73 \cdot 8-172 \cdot 9$ & 79 & 25 & 1.08 & $0 \cdot 62,1 \cdot 88$ & $1 \cdot 30$ & $0.74,2 \cdot 29$ & 1.30 & $0.73,2 \cdot 29$ \\
\hline 2 & $180 \cdot 7-223 \cdot 6$ & $173 \cdot 0-225 \cdot 0$ & 83 & 28 & 1.08 & $0.63,1.85$ & 1.29 & $0.75,2 \cdot 23$ & 1.24 & $0.72,2 \cdot 15$ \\
\hline 3 & $223 \cdot 7-268 \cdot 0$ & $225 \cdot 1-280 \cdot 0$ & 76 & 27 & 1.25 & $0 \cdot 72,2 \cdot 16$ & 1.58 & $0.90,2 \cdot 79$ & 1.69 & $0.96,3.00$ \\
\hline 4 & $268 \cdot 1-325 \cdot 2$ & $280 \cdot 1-346 \cdot 0$ & 82 & 24 & 1.00 & $0.57,1.75$ & 1.06 & $0.60,1.87$ & 1.03 & $0.58,1.81$ \\
\hline 5 & $325 \cdot 3-1475 \cdot 6$ & $346 \cdot 1-1075 \cdot 6$ & 78 & 25 & \multirow{2}{*}{\multicolumn{2}{|c|}{$\begin{array}{c}1 \\
0 \cdot 76\end{array}$}} & \multicolumn{2}{|r|}{$\begin{array}{c}1 \\
0.93\end{array}$} & \multirow{2}{*}{\multicolumn{2}{|c|}{$\begin{array}{c}1 \\
0.40\end{array}$}} \\
\hline$P$ for tren & & & & & & & & 0.93 & & \\
\hline \multicolumn{11}{|c|}{ Erythrocyte folate $(\mathrm{nmol} / \mathrm{l})$} \\
\hline 1 & $65 \cdot 7-396 \cdot 6$ & $106 \cdot 5-382 \cdot 1$ & 78 & 27 & 1.04 & $0.61,1 \cdot 78$ & 1.25 & $0.72,2 \cdot 18$ & $1 \cdot 23$ & $0 \cdot 71,2 \cdot 15$ \\
\hline 2 & $396.7-534.8$ & $382 \cdot 2-501 \cdot 2$ & 78 & 21 & 0.73 & $0.41,1.30$ & 0.89 & $0.49,1.61$ & 0.84 & $0.47,1.53$ \\
\hline 3 & $534.9-657 \cdot 1$ & $501 \cdot 3-608 \cdot 2$ & 78 & 21 & 0.75 & $0.42,1.34$ & 0.78 & $0.43,1.61$ & 0.77 & $0.43,1.38$ \\
\hline 4 & $657 \cdot 2-872 \cdot 4$ & $608 \cdot 3-805 \cdot 3$ & 79 & 31 & $1 \cdot 23$ & $0.73,2.08$ & $1 \cdot 28$ & $0 \cdot 76,2 \cdot 17$ & 1.34 & $0.79,2 \cdot 26$ \\
\hline 5 & $872 \cdot 5-2266 \cdot 0$ & $805 \cdot 4-2177 \cdot 6$ & 78 & 26 & \multirow{2}{*}{\multicolumn{2}{|c|}{$\begin{array}{c}1 \\
0.40\end{array}$}} & \multirow{2}{*}{\multicolumn{2}{|c|}{0.76}} & & 1 \\
\hline$P$ for tren & & & & & & & & & \multicolumn{2}{|r|}{0.67} \\
\hline \multicolumn{11}{|c|}{ Plasma vitamin $C(\mu \mathrm{g} / \mathrm{l})$} \\
\hline 1 & $0-14 \cdot 2$ & $0-17 \cdot 7$ & 79 & 31 & 1.86 & $1 \cdot 05,2 \cdot 30$ & 1.82 & $1 \cdot 02,3 \cdot 26$ & 1.88 & $1.05,3.37$ \\
\hline 2 & $14 \cdot 3-29 \cdot 7$ & $17 \cdot 8-36 \cdot 2$ & 80 & 22 & $1 \cdot 15$ & $0.62,2 \cdot 13$ & 1.30 & $0.70,2.42$ & 1.32 & $0.71,2.45$ \\
\hline 3 & $29 \cdot 8-45 \cdot 3$ & $36 \cdot 3-52 \cdot 0$ & 80 & 30 & $1 \cdot 81$ & $1.02,3 \cdot 22$ & 1.65 & $0.92,2.95$ & 1.69 & $0.94,3.02$ \\
\hline 4 & $45 \cdot 4-60 \cdot 6$ & $52 \cdot 1-69 \cdot 2$ & 80 & 27 & 1.56 & $0.87,2 \cdot 81$ & 1.52 & $0.84,2.75$ & 1.61 & $0.89,2.92$ \\
\hline 5 & $60 \cdot 7-137.9$ & $69 \cdot 3-131 \cdot 2$ & 79 & 19 & \multirow{2}{*}{\multicolumn{2}{|c|}{$\begin{array}{c}1 \\
0.17\end{array}$}} & \multirow{2}{*}{\multicolumn{2}{|c|}{$\begin{array}{c}1 \\
0.19\end{array}$}} & \multirow{2}{*}{\multicolumn{2}{|c|}{$\begin{array}{c}1 \\
0.17\end{array}$}} \\
\hline$P$ for tren & & & & & & & & & & \\
\hline \multicolumn{5}{|c|}{ Serum 25-OHD (nmol/l) } & & & & & & \\
\hline 1 & $6 \cdot 0-23 \cdot 0$ & $7 \cdot 0-19 \cdot 0$ & 75 & 41 & $2 \cdot 89$ & $1 \cdot 61,5 \cdot 18$ & $2 \cdot 22$ & $1.21,4.07$ & $2 \cdot 22$ & $1.22,4.06$ \\
\hline 2 & $23 \cdot 1-30 \cdot 0$ & $19 \cdot 1-24 \cdot 0$ & 86 & 34 & $2 \cdot 07$ & $1 \cdot 14,3 \cdot 76$ & 1.71 & $0.93,3.14$ & 1.75 & $0.95,3.22$ \\
\hline 3 & $30 \cdot 1-37 \cdot 0$ & $24 \cdot 1-30 \cdot 2$ & 80 & 21 & $1 \cdot 16$ & $0 \cdot 60,2 \cdot 24$ & 1.03 & $0.53,2.02$ & 1.03 & $0.53,2.00$ \\
\hline 4 & $37 \cdot 1-47 \cdot 0$ & $30 \cdot 3-39 \cdot 0$ & 78 & 17 & 1.00 & $0.50,1.97$ & 0.96 & $0.48,1.92$ & 0.92 & $0.46,1.84$ \\
\hline 5 & $47 \cdot 1-82 \cdot 0$ & $39 \cdot 1-82 \cdot 0$ & 79 & 16 & \multirow{2}{*}{\multicolumn{2}{|c|}{$\begin{array}{c}1 \\
<0.001\end{array}$}} & \multirow{2}{*}{\multicolumn{2}{|c|}{$\begin{array}{c}1 \\
0.003\end{array}$}} & \multirow{2}{*}{\multicolumn{2}{|c|}{$\begin{array}{c}1 \\
0.001\end{array}$}} \\
\hline$P$ for tren & & & & & & & & & & \\
\hline
\end{tabular}

25-OHD, 25-hydroxycholecalciferol.

*Total number of participants $n 398$ apart from ferritin $(n 396)$ and folate $(n 391)$

† Model 1, adjusted for age and sex.

$\ddagger$ Model 2 , model $1+$ taking five or more kinds of medicine and self-perceived health status.

$\S$ Model 3, model $2+$ having heart problem and/or diabetes at baseline.

$<39 \mathrm{nmol} / \mathrm{l})$ was $1.39(95 \% \mathrm{CI} 1 \cdot 17,1.65)(P=0 \cdot 01)$. While the association was not significant after adjustment for parathyroid hormone status, this could reflect the fact that parathyroid hormone status has a direct effect on vitamin D levels. Further evidence that vitamin D may have a protective effect on survival in older individuals is provided by a study of vitamin D supplementation in men and women aged 65-85 years in the UK in whom oral vitamin supplements given at 4-monthly intervals led to a reduced hazard ratio for death from all causes (hazard ratio 0.88 $(95 \%$ CI $0.74,1.06)$ ) over 5 years ${ }^{11}$.

\section{Possible mechanisms for an association between vitamin $D$ and survival}

In adults vitamin $\mathrm{D}$ deficiency causes secondary hyperparathyroidism that can precipitate and exacerbate osteoporosis and osteomalacia and hence fractures, while vitamin D deficiency has also been found to increase the risk of many other common and life-threatening diseases in old individuals, including some common cancers, CVD and type 1 diabetes ${ }^{12}$. 1,25-Dihydroxyvitamin $\mathrm{D}$ has been found to down regulate hyperproliferative cell growth, thereby possibly suppressing the development of cancer $^{13,14}$. 1,25-Dihydroxyvitamin D also has the ability to down regulate renin and angiotensin production, thereby decreasing blood pressure and CVD risk ${ }^{15}$. 1,25-Dihydroxyvitamin $\mathrm{D}$ can also activate $\mathrm{T}$ and $\mathrm{B}$ lymphocytes and macrophages which may explain the associations of vitamin $\mathrm{D}$ with the incidence of most common autoimmune diseases including type 1 diabetes ${ }^{16}$.

\section{Strength and limitations of the present study}

The participants in the present study were similar to the local population in aspects of socio-economic status ${ }^{2}$. All deaths occurring in the UK were likely to have been recorded on the $\mathrm{CHI}$ or GROS, but the lower mortality rate in the participants compared with the general population contributed to reduced power to detect associations 

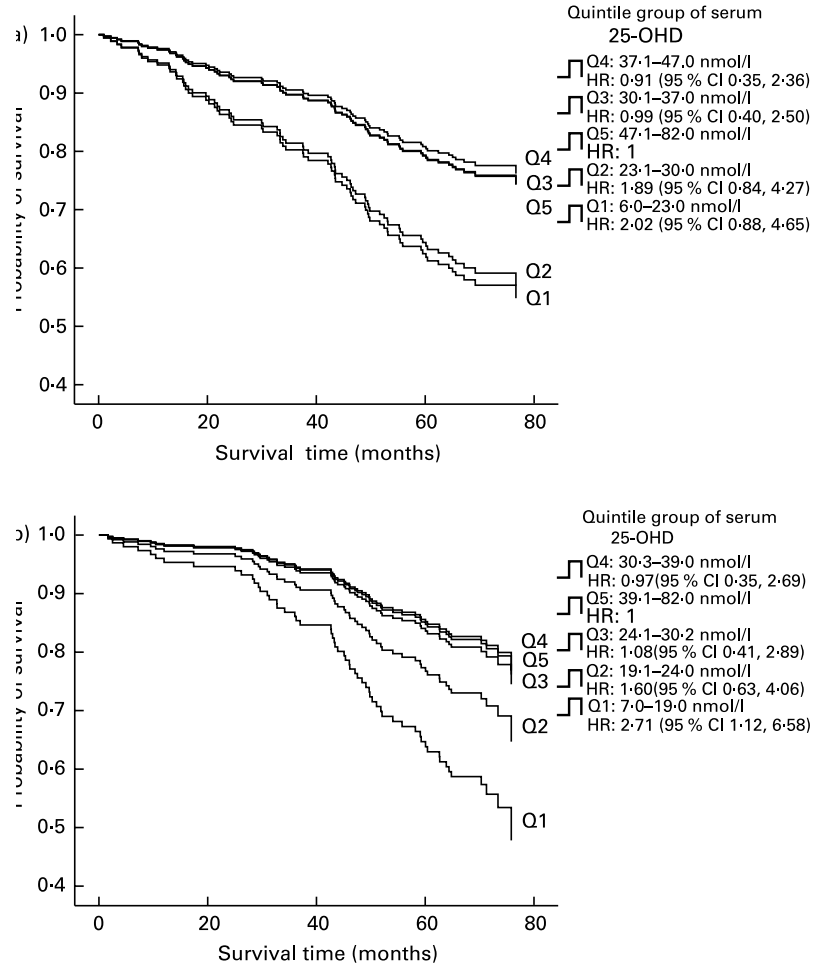

Fig. 1. Survival curves for quintiles (Q) of baseline serum 25-hydroxycholecalciferol (25-OHD) in men (a) and women (b). Hazard ratios (HR) were adjusted for variables in model 3 (see Table 2), i.e. age, taking five or more kinds of medicine, self-perceived health status and pre-existing heart disease and/or diabetes. The linear trend across quintiles was significant for both men ( $P$ for trend 0.02) and women ( $P$ for trend 0.02).

Table 3. Numbers of participant and numbers of deaths in each quintile

\begin{tabular}{|c|c|c|c|c|}
\hline \multirow[b]{2}{*}{ Quintile } & \multicolumn{2}{|r|}{ Men } & \multicolumn{2}{|c|}{ Women } \\
\hline & $n$ & Deaths $(n)$ & $n$ & Deaths $(n)$ \\
\hline 1 & 38 & 21 & 37 & 20 \\
\hline 2 & 49 & 21 & 37 & 13 \\
\hline 3 & 39 & 11 & 41 & 10 \\
\hline 4 & 39 & 9 & 39 & 8 \\
\hline 5 & 42 & 9 & 37 & 7 \\
\hline
\end{tabular}

between mortality and nutrient status. The fact that the blood samples were taken in the morning without the subjects having had fruit juice or breakfast cereal reduced the possibility of variation in vitamin $\mathrm{C}, \mathrm{Fe}$ and folate levels due to recent ingestion. However, blood nutrient levels may vary within subjects and do not necessarily reflect concentrations in other tissues.

Around half of the participants in the present study reported having heart disease at baseline, and we cannot rule out the possibility that pre-existing disease contributed to the lower vitamin $\mathrm{C}$ or vitamin $\mathrm{D}$ levels, though including pre-existing disease in the model did not affect the associations. To assess whether the associations are seen in those with no pre-existing disease would require a larger study in healthy older individuals.

\section{Summary}

In summary, we found evidence for an association between serum 25-OHD levels and all-cause mortality, with some evidence to suggest that this association might reflect reverse causation. We also found weaker evidence for an association between vitamin $\mathrm{C}$ levels and all-cause mortality. Blood vitamin D status can be increased by spending time outdoors in sunny weather, increasing intake of food rich in vitamin D such as oily fish, dairy products or fortified margarine or breakfast cereals or taking cod-liver oil or other supplements with vitamin $\mathrm{D}$, while vitamin $\mathrm{C}$ levels can be increased by increasing consumption of citrus fruit or juice or taking supplements containing vitamin C. All of these are low-cost interventions with little risk of side effects. Further randomized trials of improving dietary intake or increasing sunlight exposure in large numbers of subjects will be needed to assess whether the associations reported here could be causal and whether lifestyle changes could contribute to improved survival in older individuals.

\section{Acknowledgements}

We thank Val Angus for providing data on survival status from the CHI.

Table 4. Hazard ratios (HR) of risk of death referent to the highest quintile of serum 25-hydroxycholecalciferol concentrations (nmol/l) and significance of linear trends across sex-specific quintiles for men and women combined

\begin{tabular}{|c|c|c|c|c|c|c|c|c|c|c|c|c|}
\hline \multirow{2}{*}{$\frac{\text { Quintile }}{1}$} & \multirow{2}{*}{$\frac{\text { Men }}{6 \cdot 0-23 \cdot 0}$} & \multirow{2}{*}{$\frac{\text { Women }}{7 \cdot 0-19 \cdot 0}$} & \multirow{2}{*}{$\frac{N}{75}$} & \multirow{2}{*}{$\frac{\text { Deaths }(n)}{41}$} & \multicolumn{2}{|r|}{$\mathrm{HR}^{*}$} & \multicolumn{2}{|r|}{$\mathrm{HR} \dagger$} & \multicolumn{2}{|r|}{ HR } & \multicolumn{2}{|r|}{ HR§ } \\
\hline & & & & & 2.22 & $1.22,4.06$ & 2.02 & $1 \cdot 10,3 \cdot 72$ & 1.97 & $1.03,3.75$ & 1.74 & $0.91,3.34$ \\
\hline 2 & $23 \cdot 1-30 \cdot 0$ & $19 \cdot 1-24 \cdot 0$ & 86 & 34 & 1.75 & $0.95,3.22$ & 1.64 & $0.89,3.02$ & 1.54 & $0.80,2.97$ & 1.40 & $0.73,2 \cdot 70$ \\
\hline 3 & $30.1-37.0$ & $24 \cdot 1-30 \cdot 2$ & 80 & 21 & 1.03 & $0.53,2.00$ & 1.01 & $0.52,1.96$ & 0.95 & $0.48,1.88$ & 0.90 & $0.45,1.79$ \\
\hline 4 & $37 \cdot 1-47 \cdot 0$ & $30 \cdot 3-39 \cdot 0$ & 78 & 17 & 0.92 & $0.46,1.84$ & 0.87 & $0.43,1.75$ & 0.86 & $0.43,1.74$ & 0.80 & $0.39,1.62$ \\
\hline 5 & $47 \cdot 1-82 \cdot 0$ & $39 \cdot 1-82 \cdot 0$ & 79 & 16 & & 1 & & 1 & & 1 & & 1 \\
\hline$P$ for trend & & & & & & 0.001 & & 0.008 & & 0.01 & & 0.03 \\
\hline
\end{tabular}

${ }^{*}$ Model 3, adjusted for age, sex, taking five or more kinds of medicine, self-perceived health status and pre-existing heart disease and/or diabetes.

† Model 4, model 3+ sunlight exposure, i.e. season of blood sampling + sunbathing + outdoor physical activity.

$\ddagger$ Model 5 , model $3+$ use of a supplement containing vitamin $D$.

$\S$ Model 6, model $3+$ variables in model 4 and model 5. 


\section{References}

1. Finch S, Doyle W, Lowe C, Bates CJ, Prentice A, Smithers G \& Clarke PC (1998) National Diet and Nutrition Survey: People Aged 65 Years and Over. Volume 1: Report of the Diet and Nutrition Survey. London: The Stationery Office.

2. Hung J, Beilby J, Knuiman M \& Divitini M (2003) Folate and vitamin $\mathrm{B}_{12}$ and risk of fatal cardiovascular disease: cohort study from Busselton, Western Australia. BMJ 326, $131-137$.

3. Fletcher AE, Breeze E \& Shetty PS (2003) Antioxidant vitamins and mortality in older persons: findings from the nutrition addon study to the Medical Research Council Trial of Assessment and Management of Older People in the Community. Am J Clin Nutr 78, 999-1010.

4. Khaw K, Bingham S, Welch A, Luben R, Wareham N, Oakes S \& Day N (2001) Relation between plasma ascorbic acid and mortality in men and women in EPIC-Norfolk prospective study: a prospective population study. European Prospective Investigation into Cancer and Nutrition. Lancet 357, 657-663.

5. Simon JA, Hudes ES \& Tice JA (2001) Relation of serum ascorbic acid to mortality among US adults. $J$ Am Coll Nutr 20, 255-263.

6. Sambrook PN, Chen JS, March LM, Cameron ID, Cumming RG, Lord SR, Schwarz J \& Seibel MJ (2004) Serum parathyroid hormone is associated with increased mortality independent of 25-hydroxy vitamin D status, bone mass, and renal function in the frail and very old: a cohort study. $J$ Clin Endocrinol Metab 89, 5477-5481.

7. McNeill G, Vyvyan J, Peace H, McKie L, Seymour G, Hendry J $\&$ McPherson I (2002) Predictors of micronutrient status in men and women over 75 years old living in the community. $\mathrm{Br} J$ Nutr 88, 555-561.

8. General Register Office for Scotland (2006) General Register Office for Scotland - Family Records. www.gro-scotland.gov.uk (accessed 11 April 2006).

9. Mainous AG III, Wells B, Carek PJ, Gill JM \& Geesey ME (2004) The mortality risk of elevated serum transferrin saturation and consumption of dietary iron. Ann Fam Med 2, 139-144.

10. Dacie JV \& Lewis SM (1995) Practical Haematology, 8th ed. Edinburgh: Churchill Livingstone.

11. Trivedi DP, Doll R \& Khaw KT (2003) Effect of four monthly oral vitamin $\mathrm{D}_{3}$ (cholecalciferol) supplementation on fractures and mortality in men and women living in the community: randomised double blind controlled trial. BMJ 326, 469-474.

12. Holick MF (2004) Vitamin D: important in the prevention of cancers, type 1 diabetes, heart disease, and osteoporosis. Am J Clin Nutr 79, 362-371.

13. Feldman D, Zhao XY \& Krishnan AV (2000) Vitamin D and prostate cancer. Endocrinology 141, 5-9.

14. Lowe LC, Guy M, Mansi JL, Peckitt C, Bliss J, Wilson RG \& Colston KW (2005) Plasma 25-hydroxy vitamin D concentrations, vitamin D receptor genotype and breast cancer risk in a UK Caucasian population. Eur J Cancer 41, 1164-1169.

15. Li YC, Kong J, Wei M, Chen ZF, Liu SQ \& Cao LP (2002) 1,25-Dihydroxyvitamin $D_{3}$ is a negative endocrine regulator of the renin-angiotensin system. J Clin Invest 110, 229-238.

16. Gregori S, Giarratana N, Smiroldo S, Uskokovic M \& Adorini L (2002) A $1 \alpha$, 25-dihydroxyvitamin $\mathrm{D}_{3}$ analog enhances regulatory T-cells and arrests autoimmune diabetes in NOD mice. Diabetes 51, 1367-1374. 